\title{
Laparoscopic isolated caudate lobectomy for HCC
}

\author{
Tae-Seok Kim ${ }^{1,2}$, Choon Hyuck David Kwon² \\ 1Department of Surgery, Dongsan Medical Center, Keimyung University School of Medicine, Daegu 42601, South Korea. \\ ${ }^{2}$ Department of Surgery, Digestive Disease and Surgery Institute, Cleveland Clinic, Cleveland, OH 44195, USA.
}

Correspondence to: Prof. Choon Hyuck David Kwon, Department of Surgery, Digestive Disease and Surgery Institute, Cleveland Clinic, 2049 East 100th Street, Cleveland, OH 44195, USA. E-mail: chdkwon@gmail.com

How to cite this article: Kim TS, Kwon CHD. Laparoscopic isolated caudate lobectomy for HCC. Hepatoma Res 2021;7:31. https://dx.doi.org/10.20517/2394-5079.2021.09

Received: 28 Jan 2021 First Decision: 19 Feb 2021 Revised: 3 Mar 2021 Accepted: 19 Mar 2021 Available online: 9 Apr 2021

Academic Editors: Ho-Seong Han, Allan Tsung Copy Editor: Yue-Yue Zhang Production Editor: Yue-Yue Zhang

\begin{abstract}
Hepatocellular carcinoma (HCC) located in caudate lobectomy is not common, but caudate lobectomy is associated with technical difficulty and high degree of operative risk due to deep location of the caudate lobe and surrounding major vasculature. Recently, with advances in technology and accumulation of techniques, minimal invasive surgery has been widely performed in the field of liver surgery. However, laparoscopic isolated caudate lobectomy is still technically challenging which requires in-depth knowledge of the anatomy of the caudate and extensive experience in laparoscopic liver surgery. This review focuses on the surgical techniques and outcomes of laparoscopic isolated caudate lobectomy. Although it is difficult to make conclusion regarding oncologic outcome because only a few studies with limited case numbers have reported oncologic outcome of laparoscopic isolated caudate lobectomy for HCC, laparoscopic approach could be performed safely with several benefits and become a favorable method for isolated caudate lobectomy, especially for surgeons with relatively large experience in laparoscopic liver surgery.
\end{abstract}

Keywords: Hepatocellular carcinoma, caudate lobectomy, laparoscopic liver resection, minimal invasive surgery

\section{INTRODUCTION}

Hepatocellular carcinoma (HCC) in the caudate lobe is not commonly seen and its treatment is difficult because of the tumor's deep location surrounded by major vessels and complex blood supply $y^{[1-4]}$. Furthermore, the prognosis of HCC in the caudate lobe has been reported to be poorer than that of patients with HCC in other sites ${ }^{[2,5-8]}$. Surgical resection has been considered as the most effective treatment, but resection of the caudate lobectomy is associated with technical difficulty and high degree of operative

The Author(s) 2021. Open Access This article is licensed under a Creative Commons Attribution 4.0 International License (https://creativecommons.org/licenses/by/4.0/), which permits unrestricted use, sharing, adaptation, distribution and reproduction in any medium or format, for any purpose, even commercially, as long as you give appropriate credit to the original author(s) and the source, provide a link to the Creative Commons license, and indicate if changes were made. 
risk $^{[2,9,10]}$. In cases of large tumor, complete resection with a sufficient margin could be difficult to achieve, and combined resection with adjacent hemi-liver or other segments can be considered in patients with good liver function. However, many patients with HCC have chronic hepatitis or cirrhosis, and should undergo isolated caudate lobectomy as an alternative procedure of choice to improve curability ${ }^{[1,1,12]}$.

With the accumulation of experiences, development of surgical instruments and advancement of surgical skills, pure laparoscopic liver resection is possible in tumors located in all segments of the liver and in patients with liver cirrhosis ${ }^{[13-17]}$. However, despite the advances in laparoscopic liver surgery, resection of the caudate lobe is still one of the most technically challenging surgeries due to its deep location and proximity to major vessels including inferior vena cava (IVC), hepatic veins and hepatic hilum. For these reasons, laparoscopic caudate lobectomy has been performed in only a few experienced centers. Nervertheless, safety and feasibility of this procedure, when performed by experienced surgeons, have been reported by several experienced centers ${ }^{[18-25]}$.

The aim of this article is to review the global experiences of laparoscopic caudate lobectomy for HCC regarding the indication, technical access, surgical and oncologic outcomes based on a literature review. Literature searches were conducted using PubMed and Cochrane Library databases with terms of "Isolated caudate lobectomy", "Laparoscopic caudate lobectomy", and "Hepatocellular carcinoma in caudate lobe".

\section{ANATOMY OF THE CAUDATE LOBE}

The caudate lobe is located posterior to the right and left lobes of liver and anterior to the IVC, which may envelop this structure circumferentially. A nomenclature system for the anatomy of the caudate lobe had been debated before Kumon's subdivision classification system was established. Topographical nomenclature used for hepatic segments in the United States was proposed by Healy and Schroy ${ }^{[26]}$ : segment I left and segment I right, while nomenclature used in Europe was proposed by Couinaud ${ }^{[27]}$ : segment I and segment IX. However, Kumon ${ }^{[28]}$ classified the caudate lobe into 3 portions through the investigation using corrosion liver casts and this classification has been widely used.

The caudate lobe is an autonomous segment of the liver; it consists of 3 parts according to Kumon's nomenclature: the Spiegel lobe, the paracaval portion, and the caudate process ${ }^{[28]}$. The Spiegel lobe is located to the left of the retrohepatic IVC and the Arantius' ligament. The paracaval portion is anteriorly attached to the retrohepatic IVC by the retrohepatic ligament and the short hepatic veins. The caudate process is located anterior to the IVC, extending to the hilum of the liver just posterior to the bifurcation of the portal vein.

The portal blood flow for the caudate lobe origins from both the left and the right portal systems. According to Kumon's study, there are usually 5 (mean 4.3, range 3-6) portal venous branches and 3 (mean 3.8, range 2-6) biliary branches in the caudate lobe. The hepatic arterial flow is variable, but usually comes through a solitary branch from the main left hepatic artery and a second smaller branch from the right posterior sectional artery. A single portal vein and bile duct arising from the left branch are most commonly found in the Spiegel lobe. A single branch from the left portal vein predominantly feeds the paracaval portion but the bile duct drains to the right or left system in almost equal frequencies. And for the caudate process, the portal vein usually branches from the right portal vein and the bile duct from the right posterior hepatic duct $^{[28]}$. Venous drainage occurs along the posterior aspect of the caudate lobe directly into the IVC through multiple short hepatic veins which vary in number and size ${ }^{[29]}$. 


\section{SELECTION OF APPROACH FOR CAUDATE LOBECTOMY \& SURGICAL TECHNIQUES}

Different approaches for isolated caudate lobectomy by open approach were reported previously; the posterior or right-side approach by Yanaga et al. ${ }^{[30]}$, the left-side approach by Colonna et al. ${ }^{[31]}$, and the anterior approach by Yamamoto et al.$^{[32]}$ have been commonly used. The type of approach is determined depending on the tumor size and location; the left-sided approach is suitable for Spiegel lobe resection and the posterior or right-side approach is used for paracaval or caudate process lesions. For the case of whole caudate lobe involvement, the left-sided and right-sided combined approach can be used ${ }^{[33]}$.

For left-sided approach, exposure is facilitated through retraction of left lateral section to the right after division of the falciform, coronary, and triangular ligaments. Once excision of the lesser omentum is completed, the Spiegel lobe can be seen and the dissection is performed from caudal to cranial and left to right direction. The hepatocaval ligament covering the retrohepatic IVC is divided to free the left lateral border and better expose the upper area of the IVC. The Spiegel lobe can then be retracted upward to expose the short hepatic veins which upon dissection frees the caudate lobe from the retrohepatic IVC. The portal triads to the Spiegel lobe are then exposed, dissected, and clipped. After that, the liver parenchyma is transected starting from the caudal side along the IVC up to the border for adequate margin. Division of the Arantius' ligament frees the upper boundary of the caudate lobe from segment 4 and aids in isolating the confluence of the left hepatic vein into the $\operatorname{IVC}^{[29]}$.

For right-sided approach, the retroperitoneum covering the infrahepatic IVC is divided after right liver mobilization and the right adrenal gland is detached from the liver. The hepatocaval ligament is divided and the liver is retracted to the left side to expose the short hepatic veins. The short hepatic veins into IVC are exposed, clipped and divided from caudal to cranial up to the level of the confluence of the right hepatic vein into the IVC. Retraction of the hepatoduodenal ligament to the left better exposes the caudate process. The anterior border of the resection plane is the posterior Glissonean pedicle from which portal branches to the caudate process can be identified. Ligation of these branches will show the anatomical transection border and parenchymal transection is carried out up to cranially until the confluence of the right hepatic

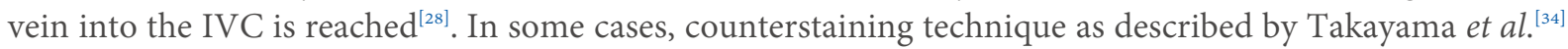
may be useful for better delineating the borders.

The transection of the liver parenchyma and management of bleeding can be challenging because of the deep lying surgical field. Adequate mobilization of caudate lobe allows better visualization, which can minimize major vascular injury during parenchymal dissection. Meticulous dissection of individual branches of the portal vein, bile duct and short hepatic veins is important and keeping dissection plane along the exact anatomical landmark helps reduce bleeding and bile leakage. Energy devices or cavitron ultrasonic surgical aspirator is usually used. Bipolar eletrocautery especially comes handy when dissection and managing bleeding from the short hepatic veins since it very effectively controls small bleeding from veins. Ultrasonography can help to better understand the anatomic location of important vascular structures such as the middle or right hepatic veins ${ }^{[18]}$. The interruption of blood inflow by Pringle manuever can offer additional bleeding control during the dissection.

\section{LAPAROSCOPIC APPROACH FOR CAUDATE LOBECTOMY}

The overall approach and procedures practiced in laparoscopic approach are not different much from open caudate lobectomy. Small lesions located on the Spiegel's lobe are most readily approached from the left side, and lesions requiring the removal of paracaval caudate or the caudate process will need additional approach from the right side. The indication of purely laparoscopic isolated caudate lobectomy for HCC regarding tumor size and location is not established yet. However, the location and the size of the tumor are 
important determinants of indication for purely laparoscopic isolated caudate lobectomy. Large tumors located at the Spiegel's lobe are readily accessible by laparoscopic approach and so are small tumors less than $5 \mathrm{~cm}$ located at the paracaval or at the caudate process. However, tumors larger than $5 \mathrm{~cm}$ located at the paracaval or caudate process would prove to be much more challenging. Theoretically, similar approach to open surgery such as described by Yamamoto et al. ${ }^{[32]}$ could be feasible but this method has not been described yet in the literature and needs to be tested. Furthermore, combined resection of the vena cava is possible in case the tumor is invaded to or cannot be detached from the IVC and is not an absolute contraindication. The author has performed a case with partial vena cava resection (unpublished) and there has been a recent publication that has been performed in a similar fashion by applying laparoscopic vascular clamps superior and inferior of the resected IVC by purely laparoscopic method with successful results ${ }^{[35]}$. Nevertheless, irrespective of method of approach, we must remember that it is more important to retain proper oncologic standards rather than be too preoccupied by which approach the operation had been performed.

Understanding the anatomy is essential and laparoscopic caudate lobectomy is considered to be a difficult procedure demanding different surgical strategies because of unique anatomy of the caudate lobe. Nevertheless, laparoscopic approach provides some unique advantages compared to open surgery that makes laparoscopic approach a much more attractable relative to other lesions located in other segments of the liver. Traditionally, for open approach, large incision and extensive mobilization are necessary and even so, visibility remains very limited because of the deep location and its surrounding major vascular structures. In the contrary, because of its intrinsic "caudal approach" nature in laparoscopic surgery, the plane lying posteriorly such as between the caudate lobe and the retrohepatic IVC can easily be seen through the scope without the need for an extensive dissection ${ }^{[36]}$. The reverse Trendelenburg position of the patient further improves exposure by gravitationally shifting visceral structures away from the liver hilum $^{[29]}$. Magnified view shown in high-definition display unit allows clear visualization of the small vessels and bile ducts often found in caudate lobes and facilitates precision surgery. The flexible scope provides various approaching angles which can further improve the quality of the operation ${ }^{[21]}$. Some have used infrared indocyanine green fluorescence technology to better visualize the targeted lesion ${ }^{[29,37]}$.

It is well known that laparoscopic approach reduces bleeding, especially from veins by increasing intraabdominal pressure during surgery. Estimated blood loss during laparoscopic isolated caudate lobectomy has not been shown to increase according to previous reports and it can be performed safely under experienced hands. The presence of pneumoperitoneum provides better bleeding control especially when working near the IVC and hepatic veins and bleeding control may be done under better visualization ${ }^{[2,29,38]}$. For these reasons, the previous comparative study by Xu et al. ${ }^{[33]}$ reported comparable or better results in estimated blood loss and operation time compared to those of open caudate lobectomy. The laparoscopic ultrasonic shear device and the bipolar forceps that have traditionally not been widely used in open surgery, have been especially useful when dissecting the liver away from the IVC. And lastly, the resected specimen is usually not large which only requires a small extension of one of the $12 \mathrm{~mm}$ port site incisions to extract the specimen, further adding improved patient recovery and shorter hospital stay.

\section{SURGICAL AND ONCOLOGIC OUTCOMES}

Because isolated tumor in caudate lobe is relatively infrequent and caudate lobectomy requires advanced laparoscopic surgical skills, laparoscopic isolated caudate lobectomy has been mostly reported from highvolume, experienced centers and data have been limited to case reports or small case series. Despite these limitations, favorable perioperative outcomes compared to open caudate lobectomy regarding operation time, intraoperative bleeding, and perioperative morbidity have been reported. However, these results are 
based on the premise that this procedure would be performed by experienced surgeons in laparoscopic liver resection who have profound anatomical knowledge ${ }^{[18-24,29,39]}$.

The oncologic outcomes of HCC of the caudate lobe have been controversial. Takayasu et al. ${ }^{[5]}$ reported that HCC in the caudate lobe readily develops intrahepatic metastases because of the frequent portal and/or venous infiltration found due to its anatomical characteristics and according to a study by Tanaka et al. ${ }^{[6]}$, the patients with caudate lobe HCC showed significantly more intrahepatic recurrence and poorer survival rate compared to the patients with HCC in other lobes. On the contrary, others reported that the survival rates of patients with caudate lobe HCC were not different. Other factors such as vascular invasion, satellite nodules, tumor size, tumor marker and severe fibrosis have been shown to impact survival irrespective of tumor location ${ }^{[40-42]}$. Only a few studies with limited case numbers have reported oncologic outcome of laparoscopic isolated caudate lobectomy for HCC, and thus it is difficult to make any conclusions regarding the oncologic safety, but negative resection margin rates are acceptable ${ }^{[19,21,29]}$. Long term oncologic safety will need to be confirmed with further studies including a large cohorts with longer follow up data.

\section{CONCLUSIONS}

Laparoscopic caudate lobectomy is a technically challenging surgery that requires in-depth knowledge of the anatomy of the caudate and extensive experience in laparoscopic liver surgery to perform it safely. However, laparoscopic approach for caudate lesions has advantages that are uniquely beneficial compared to open surgery. The typical caudal view seen in laparoscopic surgery and the magnified view on high-definition screen provide precision surgery necessary while the small size of resected specimen only requires a small incision, maximizing the benefit of minimal invasive approach. For these reasons, laparoscopic approach is an exceptionally favorable method of approach for isolated caudate lobectomy and worth an aggressive approach, especially for surgeons with relatively large experience in laparoscopic liver surgery.

\section{DECLARATIONS}

\section{Authors' contributions}

Researched public database and wrote manuscript: Kim TS, Kwon CHD

Designed, edited and approved manuscript: Kwon CHD

\section{Availability of data and materials}

Not applicable.

\section{Financial support and sponsorship}

None.

\section{Conflicts of interest}

All authors declared that there are no conflicts of interest.

\section{Ethical approval and consent to participate}

Not applicable.

\section{Consent for publication}

Not applicable.

\section{Copyright}

(c) The Author(s) 2021. 


\section{REFERENCES}

1. Shimada M, Matsumata T, Maeda T, Yanaga K, Taketomi A, Sugimachi K. Characteristics of hepatocellular carcinoma originating in the caudate lobe. Hepatology 1994;19:911-5. PubMed

2. Chaib E, Ribeiro MA, Jr., Silva Fde S, Saad WA, Cecconello I. Surgical approach for hepatic caudate lobectomy: review of 401 cases. J Am Coll Surg 2007;204:118-27. DOI PubMed

3. Kim HC, Chung JW, Jae HJ, et al. Caudate lobe hepatocellular carcinoma treated with selective chemoembolization. Radiology 2010;257:278-87. DOI PubMed

4. Kim HC, Miyayama S, Chung JW. Selective chemoembolization of caudate lobe hepatocellular carcinoma: anatomy and procedural techniques. Radiographics 2019;39:289-302. DOI PubMed

5. Takayasu K, Muramatsu Y, Shima Y, et al. Clinical and radiologic features of hepatocellular carcinoma originating in the caudate lobe. Cancer 1986;58:1557-62. DOI PubMed

6. Tanaka S, Shimada M, Shirabe K, et al. Surgical outcome of patients with hepatocellular carcinoma originating in the caudate lobe. Am J Surg 2005;190:451-5. DOI PubMed

7. Lu CL, Wu JC, Chiang JH, Lui WY, Chau GY, Lee SD. Hepatocellular carcinoma in the caudate lobe: early diagnosis and active treatment may result in long-term survival. J Gastroenterol Hepatol 1997;12:144-8. DOI PubMed

8. Terayama N, Miyayama S, Tatsu H, et al. Subsegmental transcatheter arterial embolization for hepatocellular carcinoma in the caudate lobe. J Vasc Interv Radiol 1998;9:501-8. DOI PubMed

9. Philips P, Farmer RW, Scoggins CR, McMasters KM, Martin RC, 2nd. Caudate lobe resections: a single-center experience and evaluation of factors predictive of outcomes. World J Surg Oncol 2013;11:220. DOI PubMed PMC

10. Liu P, Yang JM, Niu WY, et al. Prognostic factors in the surgical treatment of caudate lobe hepatocellular carcinoma. World $J$ Gastroenterol 2010;16:1123-8. DOI PubMed PMC

11. Nagasue N, Kohno H, Yamanoi A, et al. Resection of the caudate lobe of the liver for primary and recurrent hepatocellular carcinomas. J Am Coll Surg 1997;184:1-8. PubMed

12. Sakoda M, Ueno S, Kubo F, et al. Surgery for hepatocellular carcinoma located in the caudate lobe. World J Surg 2009;33:1922-6. DOI PubMed

13. Han HS, Shehta A, Ahn S, Yoon YS, Cho JY, Choi Y. Laparoscopic versus open liver resection for hepatocellular carcinoma: Casematched study with propensity score matching. J Hepatol 2015;63:643-50. DOI PubMed

14. Cheung TT, Poon RT, Lo CM: Reply to letter: "long-term survival analysis of pure laparoscopic versus open hepatectomy for hepatocellular carcinoma in patients with cirrhosis: A single-center experience".

Ann Surg 2015;262:e20-1. DOI PubMed

15. Kim KH, Jung DH, Park KM, et al. Comparison of open and laparoscopic live donor left lateral sectionectomy. Br J Surg 2011;98:1302-8. DOI PubMed

16. Ciria R, Cherqui D, Geller DA, Briceno J, Wakabayashi G. Comparative short-term benefits of laparoscopic liver resection: 9000 cases and climbing. Ann Surg 2016;263:761-77. DOI PubMed

17. Jin B, Chen MT, Fei YT, Du SD, Mao YL. Safety and efficacy for laparoscopic versus open hepatectomy: a meta-analysis. Surg Oncol 2018;27:A26-34. DOI PubMed

18. Dulucq JL, Wintringer P, Stabilini C, Mahajna A. Isolated laparoscopic resection of the hepatic caudate lobe: Surgical technique and a report of 2 cases. Surg Laparosc Endosc Percutan Tech 2006;16:32-5. DOI PubMed

19. Chen KH, Jeng KS, Huang SH, Chu SH. Laparoscopic caudate hepatectomy for cancer--an innovative approach to the no-man's land. $J$ Gastrointest Surg 2013;17:522-6. DOI PubMed

20. Salloum C, Lahat E, Lim C, et al. Laparoscopic isolated resection of caudate lobe (segment 1): A safe and versatile technique. $J$ Am Coll Surg 2016;222:e61-6. DOI PubMed

21. Oh D, Kwon CH, Na BG, et al. Surgical techniques for totally laparoscopic caudate lobectomy. J Laparoendosc Adv Surg Tech A 2016;26:689-92. DOI PubMed

22. Araki K, Fuks D, Nomi T, et al. Feasibility of laparoscopic liver resection for caudate lobe: technical strategy and comparative analysis with anteroinferior and posterosuperior segments. Surg Endosc 2016;30:4300-6. DOI PubMed

23. Jin B, Jiang Z, Hu S, et al. Surgical technique and clinical analysis of twelve cases of isolated laparoscopic resection of the hepatic caudate lobe. Biomed Res Int 2018;2018:5848309. DOI PubMed PMC

24. Cai X, Zhao J, Wang Y, et al. A left-sided, purely laparoscopic approach for anatomic caudate hepatectomy: a single-center experience. J Laparoendosc Adv Surg Tech A 2016;26:103-8. DOI PubMed

25. Ho KM, Han HS, Yoon YS, et al. Laparoscopic total caudate lobectomy for hepatocellular carcinoma. J Laparoendosc Adv Surg Tech A 2017;27:1074-8. DOI PubMed

26. Healey JE, Jr. , Schroy PC. Anatomy of the biliary ducts within the human liver; analysis of the prevailing pattern of branchings and the major variations of the biliary ducts. AMA Arch Surg 1953;66:599-616. DOI PubMed

27. Couinaud C. Le foie: etudes anatomiques et chirugicales. Paris: Masson \& Cie; 1957.

28. Kumon M. Anatomical study of the caudate lobe with special reference to portal venous and biliary branches using corrosion liver casts and clinical application. Liver Cancer 2017;6:161-70. DOI PubMed PMC

29. Cappelle M, Aghayan DL, van der Poel MJ, et al. A multicenter cohort analysis of laparoscopic hepatic caudate lobe resection. Langenbecks Arch Surg 2020;405:181-9. DOI PubMed

30. Yanaga K, Matsumata T, Hayashi H, Shimada M, Urata K, Sugimachi K. Isolated hepatic caudate lobectomy. Surgery 1994;115:757- 
61. PubMed

31. Colonna JO, 2nd, Shaked A, Gelabert HA, Busuttil RW. Resection of the caudate lobe through "bloody gultch". Surg Gynecol Obstet 1993;176:401-2. PubMed

32. Yamamoto J, Kosuge T, Shimada K, Yamasaki S, Takayama T, Makuuchi M. Anterior transhepatic approach for isolated resection of the caudate lobe of the liver. World J Surg 1999;23:97-101. DOI PubMed

33. Xu G, Tong J, Ji J, et al. Laparoscopic caudate lobectomy: a multicenter, propensity score-matched report of safety, feasibility, and early outcomes. Surg Endosc 2021;35:1138-47. DOI PubMed

34. Takayama T, Midorikawa Y, Higaki T, et al. Algorithm for resecting hepatocellular carcinoma in the caudate lobe. Ann Surg 2019. DOI PubMed

35. Vega EA, Nicolaescu DC, Salehi O, et al. Laparoscopic segment 1 with partial ivc resection in advanced cirrhosis: how to do it safely. Ann Surg Oncol 2020;27:1143-4. DOI PubMed

36. Wakabayashi G, Cherqui D, Geller DA, Han HS, Kaneko H, Buell JF. Laparoscopic hepatectomy is theoretically better than open hepatectomy: preparing for the 2nd international consensus conference on laparoscopic liver resection. J Hepatobiliary Pancreat Sci 2014;21:723-31. DOI PubMed

37. Aoki T, Murakami M, Koizumi T, et al. Determination of the surgical margin in laparoscopic liver resections using infrared indocyanine green fluorescence. Langenbecks Arch Surg 2018;403:671-80. DOI PubMed

38. TT: Technical notes on pure laparoscopic isolated caudate lobectomy for patient with liver cancer. Transl Gastroenterol Hepatol 2016;1:56. DOI PubMed PMC

39. Parikh M, Han HS, Cho JY, D'Silva M: Laparoscopic isolated caudate lobe resection. Sci Rep 2021;11:4328. DOI PubMed PMC

40. Ikegami T, Ezaki T, Ishida T, Aimitsu S, Fujihara M, Mori M. Limited hepatic resection for hepatocellular carcinoma in the caudate lobe. World J Surg 2004;28:697-701. DOI PubMed

41. Yamamoto T, Kubo S, Shuto T, et al. Surgical strategy for hepatocellular carcinoma originating in the caudate lobe. Surgery 2004;135:595-603. DOI PubMed

42. Sakamoto Y, Nara S, Hata S, et al. Prognosis of patients undergoing hepatectomy for solitary hepatocellular carcinoma originating in the caudate lobe. Surgery 2011;150:959-67. DOI PubMed 